\title{
MATRICES DECOLONIZADORAS EN LA COMUNICACIÓN \\ PARA ENTABLAR UN DIÁLOGO CON OCCIDENTE
}

Decolonizing matrices in the communication

to enter into a dialogue with the West

\author{
ORLANDO E. VALDEZ-LÓPEZ* \\ Universidad de Huelva / España \\ orlandoesteban.valdez117@alu.uhu.es \\ Código Orcid: https://orcid.org/0000-0001-6038-7313 \\ LUIS M. ROMERO-RODRÍGUEZ \\ Universidad Internacional de La Rioja / España \\ ESAl Business School, Universidad Espíritu Santo / Ecuador \\ luismiguel.romero@unir.net \\ Código Orcid: https://orcid.org/0000-0003-3924-1517 \\ ÁNGEL HERNANDO GÓMEZ ${ }^{* * *}$ \\ Universidad de Huelva / España \\ angel.hernando@dpsi.uhu.es \\ Código Orcid: https://orcid.org/0000-0002-6414-5415
}

Forma sugerida de citar: Valdez, Orlando, Romero, Luis \& Gómez, Ángel (2019). Matrices decolonizadoras en la comunicación para entablar un diálogo con Occidente. Sophia, colección de Filosofía de la Educación, 26(1), pp. 281-305.

* Licenciado en Comunicación Social, máster en Educación Superior, diplomado en Derechos Humanos y Justicia Restaurativa en el Ejercicio Periodístico, profesor de la Carrera de Comunicación de la Universidad Técnica de Oruro, doctorando interuniversitario en Comunicación: Educomunicación y Alfabetización Mediática.

** Docente nivel III de la Universidad Internacional de La Rioja (España) y profesor invitado del ESAI Business School de la Universidad Espíritu Santo (Ecuador). Doctor en Comunicación, máster en Comunicación, editor adjunto de la Revista Comunicar, editor jefe de la Revista Retos y miembro del Grupo de Investigación Ágora de la Universidad de Huelva (PAI-HUM-648).

*** Profesor titular en el Departamento de Psicología Social, Evolutiva y de la Educación de la Universidad de Huelva, doctor en Psicología, editor adjunto de la Revista Comunicar y miembro del Grupo de Investigación Ágora de la Universidad de Huelva (PAI-HUM-648). 


\title{
Resumen
}

El presente trabajo examina las premisas de la decolonización en el estudio y la práctica comunicacional que interpela a Occidente en base al pensamiento crítico de intelectuales precursores y contemporáneos de América Latina. Se recuperan principios y valores de la cosmovisión andinaamazónica para la constitución de un estudio y ejercicio de la comunicación intercultural para el "vivir bien", evidenciándose la necesidad de una epistemología de comunicación alternativa con base a matrices formuladas por autores como Luis Ramiro Beltrán y Erick Torrico, bajo la premisa de la "comunicología de la liberación" frente al progreso-mercantilismo y modernidad de la comunicación. Este enfoque repercute en la horizontalidad y circularidad del proceso comunicativo, y sobre todo en la recuperación de su nivel ontológico e integral en el estudio-saber y ejercicio-hacer de la comunicación. La filosofía andina-amazónica no pretende la anulación de la forma de razonar y proceder de Occidente, sin embargo, busca diálogo y respeto al saber indígena y a la vida comunitaria. En consecuencia, se quiere la unidad en la diversidad, entendida como la comprensión igualitaria del pensamiento de la otredad comunicativa, demostrándose la necesidad de entablar un diálogo de conocimientos entre la sabiduría indígena-nativa y el conocimiento de Occidente, asumiendo como reto instar a vivir en armonía entre los seres humanos y la naturaleza, donde la comunicación sea el vínculo para el estudio y la práctica de la cultura de la vida.

Palabras clave

Comunicación intercultural, descolonización, filosofía cultural, vida comunitaria, conocimiento, diálogo.

\begin{abstract}
This paper examines the premises of decolonization in the Communication Studies and practice that challenges the West civilization based on the critical thinking of precursors and contemporary intellectuals of Latin America. The principles and values of communication and life are recovered for the constitution of a study and the exercise of intercultural communication for well-living, evidencing the need for an alternative communication epistemology based on matrices formulated by authors such as Luis Ramiro Beltrán and Erick Torrico under the premise of "liberation communicology" against the progress-mercantilism and the modernity of communication. This approach focuses on the horizontality and the circularity of the communicative process, and above all in the recovery of its ontological and integral level in the study-knowledge and exercise of communication. Philosophy and the Amazon do not claim the annulment of the way of reasoning and the Western procedure, the embargo, the search for dialogue and respect for indigenous wisdom and community life. Consequently, unity in diversity is sought, understood as the comprehensive understanding of the thought of communicative communication, demonstrating the need to establish a dialogue of knowledge between indigenous wisdom and knowledge of the West, assuming as a challenge to urge to live in harmony between human beings and nature, where communication is the link for the study and practice of the culture of life.
\end{abstract}

\section{Keywords}

Intercultural communication, decolonization, cultural philosophy, community life, knowledge, dialogue.

\section{Introducción}

\section{Uno de los impulsores trascendentales del pensamiento latinoamerica- no de la comunicación fue sin lugar a dudas el orureño-boliviano Luis}


Ramiro Beltrán Salmón, que hizo frente a la teoría norteamericana de la comunicación a partir de la década de los sesenta, y su práctica subsecuente de comunicación horizontal como planteamiento esencial de una "comunicación liberadora", frente a imposiciones de modelos de comunicación foráneos como los de Estados Unidos y la Escuela de Frankfurt.

Beltrán (2007) reivindica en sus textos el ejercicio de la comunicación alternativa, donde los actores y facilitadores de la comunicación recrean el modelo horizontal de acceso, diálogo y participación entre los sujetos, para la generación de su propio desarrollo desde sus saberes ancestrales, como una forma inclusiva de cambio social.

El ideal, en ese contexto, fue conformar una Escuela Latinoamericana de Comunicación, sin embargo, estos esfuerzos fueron aislados en la región, porque los investigadores siguieron las pautas de teorías foráneas, tal como lo refiere el trabajo de González-Samé, Romero-Rodríguez y Aguaded (2017):

En ese sentido, no se evidencia con meridiana claridad la existencia de una "escuela latinoamericana de comunicación", pues los esfuerzos de investigación de la región han seguido las orientaciones conceptuales, epistemológicas y metodológicas provenientes de Europa y Estados Unidos, por lo que los estudios latinoamericanos han surgido históricamente como agrupaciones de estudios dispersos (p. 429).

Ante la cuestión de la inexistencia de dicha escuela de comunicación y con el propósito de unificar criterios de los comunicólogos de Latinoamérica y avizorar una propuesta propia desde la región, se debe insistir en el consenso; entonces, de acuerdo con González-Samé, Romero-Rodríguez y Aguaded (2017), vale decir que:

Es necesario renovar la investigación en comunicación en Latinoamérica, tomando como retos explorar temas innovadores, otras metodologías y nuevos enfoques. Debe existir una conexión directa con la realidad cotidiana, alimentando las motivaciones de los investigadores en este campo, buscando alternativas para la producción, así como también instrumentando quizás sus propias estrategias de difusión. La investigación en comunicación avanzará a pasos agigantados en el continente siempre y cuando exista una interrelación con responsabilidad compartida entre investigadores, universidades, empresas y el Estado (p. 16).

En ese esfuerzo, se plantea una mirada indígena del saber ancestral de cosmovisión andina-amazónica, que tiene como premisa fundamental respetar la vida en su relación armónica con la naturaleza y el cosmos, que constituye la condición principal para la vida terrenal. En cambio, 
el mundo moderno tiene como fin último el progreso, sin importar que para ello se destruya la vida en el planeta. Así, el objetivo central del presente trabajo es analizar y evidenciar los principios y valores de la cosmovisión andina-amazónica constituida en la categoría "decolonizadora" respecto del ejercicio comunicacional. Asimismo, se propone reflexionar sobre la necesidad del diálogo del conocimiento indígena con el conocimiento occidental respecto del progreso y el ejercicio del poder en detrimento del planeta.

En ese propósito, el presente trabajo se ocupa precisamente de esa "comunicología de la liberación" que basa su comprensión y acción en la cosmovisión andina-amazónica, cuyos resabios contienen profunda relación con la cultura de la vida en el planeta y en base a ello se analiza y plantea una comunicología decolonial-liberadora, como forma de reivin284 dicación, protesta y planteamiento de un diálogo de saberes con el conocimiento occidental, para salvar y preservar la casa común, el planeta Tierra.

Se aborda el tema desde el punto de vista crítico de autores latinoamericanos y especialmente bolivianos como Beltrán (2007), Torrico (2015a) y Contreras (2014), sobre el estado de la colonialización/decolonialización del poder, saber y ser, y se suma el hacer en el análisis, para confirmar rasgos definitorios que conlleven una postura crítica latinoamericana frente a la ciencia occidental.

La metodología de investigación empleada consiste en la revisión documentada de las propuestas de varios autores en este campo, así como de premisas que son fundamentadas por autores locales sobre principios y valores ancestrales, desde un tratamiento hermenéutico. En ese sentido, se procede a la presentación de categorías formuladas por autores latinoamericanos sobre colonialidad y decolonialidad. Se desglosan principios y valores de la cosmovisión andina-amazónica del "vivir bien" y se interponen puntos de vista críticos sobre el ejercicio del poder. Correspondientemente, se formula la comunicación alternativa en el entramado del rimanakuy allin kawsaypaq y se vaticina el horizonte de una comunicología decolonizada en Latinoamérica, como forma de diálogo de saberes respecto del conocimiento occidental.

\section{El Grupo Modernidad/Colonialidad}

De forma original, el Grupo Modernidad/Colonialidad (M/C) efectúa una crítica seria a la ciencia moderna instaurada en América Latina. En ese sentido, Aníbal Quijano citado por Castro-Gómez y Grosfoguel 
(2007) en la obra El giro decolonial: reflexiones para una diversidad epistémica más allá del capitalismo global, reafirma la posición de estos sustentos teóricos en el recorrido "colonialista", que abarca un colonialismo interno en países que fueron colonizados:

Colonialidad es un concepto diferente, aunque vinculado con el concepto de colonialismo. Este último se refiere estrictamente a una estructura de dominación y explotación, donde el control de la autoridad política, de los recursos de producción y del trabajo de una población determinada lo detenta otra de diferente identidad, y cuyas sedes centrales están, además, en otra jurisdicción territorial. Pero no siempre, ni necesariamente, implica relaciones racistas de poder. El colonialismo es, obviamente, más antiguo, en tanto que la colonialidad ha probado ser, en los últimos quinientos años, más profunda y duradera que el colonialismo. Pero sin duda fue engendrada dentro de este $y$, más aún, sin él no habría podido ser impuesta en la intersubjetividad del mundo, de modo tan enraizado y prolongado. Pablo González Casanova (1965) y Rodolfo Stavenhagen (1965) propusieron llamar "colonialismo interno" al poder racista/etnicista que opera dentro de un Estado-Nación. Pero eso tendría sentido solamente desde una perspectiva eurocéntrica sobre el Estado-Nación (p. 93).

Según la revista digital del pensamiento crítico latinoamericano Pacarina del Sur (Melgar, 2015), el denominado "proyecto modernidad/ colonialidad/descolonialidad" es una perspectiva dentro del pensamiento crítico latinoamericano que ha abierto nuevos espacios de producción y reflexión sobre el escenario latinoamericano. Dicho proyecto se compone a fines de los años noventa con la conjunción de varios intelectuales como: Aníbal Quijano (Perú), Enrique Dussel (Argentina-México), Edgardo Lander (Venezuela), Arturo Escobar (Colombia), Catherine Walsh (Ecuador), Nelson Maldonado-Torres (Puerto Rico), Zulma Palermo (Argentina), Santiago Castro-Gómez (Colombia), Fernando Coronil (Venezuela) y Walter Mignolo (Argentina-EE.UU.). Dichos nombres integran la lista de las figuras principales vinculadas a este colectivo y provienen casi en su totalidad de antiguos ámbitos de producción de conocimiento crítico en América Latina como la teoría de la dependencia, la filosofía de la liberación y los estudios subalternos.

En consecuencia, la revisión analítica de la literatura de los autores del M/C ut supra referidos, relata la existencia de tres tipos de colonialidades que se ejercitan con supremacía: la colonialidad del poder, colonialidad del saber y colonialidad del ser. 


\section{Tipos de colonialidad}

Colonialidad del poder. Para Quijano (2015), la colonialidad del poder es un concepto que da cuenta de uno de los elementos fundantes del actual patrón de poder, la clasificación social básica y universal de la población del planeta en torno de la idea de "raza". Es la más profunda y perdurable expresión de la dominación colonial y fue impuesta sobre toda la población del planeta en el curso de la expansión del colonialismo europeo. Desde entonces, en el actual patrón mundial de poder impregna todas y cada una de las áreas de existencia social, y constituye la más profunda y eficaz forma de dominación social, material e intersubjetiva $y$, por eso mismo, es la base intersubjetiva más universal de dominación política dentro del actual patrón de poder.

Colonialidad del saber. Edgardo Lander (2000) refiere que la colonialidad del saber es la fuerza hegemónica del pensamiento neoliberal, su capacidad de presentar su propia narrativa histórica como el conocimiento objetivo, científico y universal, y su visión de la sociedad moderna como la forma más avanzada -pero igualmente normal- de la experiencia humana, estando sustentada en condiciones histórico-culturales específicas. Entonces, la colonialidad del saber se comprende como la serie de la epistemología y las tareas generales de producción del conocimiento bajo el régimen de dominación del intelecto colonial.

Colonialidad del ser. Maldonado-Torres, en el texto El giro decolonial (2007), manifiesta que la colonialidad del ser es un concepto que deviene de la colonialidad del poder y del saber, referido a la experiencia vivida de la colonización y su impacto en el lenguaje.

A estas tres conceptualizaciones se suma la reflexión sobre dos axiomas, como una propuesta conceptual general para el debate:

Colonialidad del hacer. Torrico (2015b) indica que la comunicación occidental está relacionada con el poder de los medios o sobre los medios, quedando enfatizado, así, su lado o su empleo instrumental. Entonces, de la explotación y dominación económica y política, de la imposición de modos de pensar positivistas y de la imposición del lenguaje y comportamientos por la colonización, existe también una "colonialidad del hacer", cuyo rasgo conceptual sería la imposición de los formatos modernos para los quehaceres corpóreos-manuales, que desplazan las habilidades originarias.

Colonialidad del sueño. Desde la reflexión de Quijano (2014), subyace un razonamiento profundo respecto a la idea del sueño y la comunicación, que resulta sumamente pernicioso porque es una vía de control colonial-capitalista que aún no se discute. Es la "colonialidad del sueño" 
donde las industrias culturales euro-occidentales están controlando la visión personal de la sociedad desde la aparición de los medios masivos, y ahora más que nunca, a través del cine (hollywoodense, europeo, asiático y otros con apego al sistema capitalista) y los videojuegos en internet. Se están introduciendo dispositivos persuasivos en los sueños especialmente de los jóvenes, con categorías como el estatus moderno-colonial que significan la añoranza de la moda, lo ficticio, el terror, el sexo, el odio racial y otros placeres y males de la razón de ser, propios de la dinámica capitalista. Entonces, los sueños de una vida en plenitud están siendo soterrados por la colonialidad del sueño norteamericano/europeo/asiático, pues es la clave primero colonializar los sueños de los marginales y mestizos, y luego inculcar el deseo occidental en el hacer, saber, ser y poder.

\section{Colonialización/decolonialización}

En posturas más contemporáneas y englobando la crítica del pensamiento latinoamericano, Aníbal Quijano (2014), en la colección Antologías Esenciales del Consejo Latinoamericano de Ciencias Sociales (CLACSO), Cuestiones y horizontes de la dependencia histórico-estructural a la colonialidad/descolonialidad del poder, advierte un proceso de completa reconfiguración de la "colonialidad global del poder" como patrón de poder hegemónico en el planeta. Se trata, en primer término, de la aceleración y profundización de una tendencia a la re-concentración del control del poder en los siguientes puntos:

La re-privatización de los espacios públicos, del Estado en primer término. La reconcentración del control del trabajo [...] la exacerbación de la "explotación de la naturaleza" [...] la manipulación y control de los recursos tecnológicos de comunicación y de transporte para la imposición global de la tecnocratización/instrumentalización de la Colonialidad/Modernidad [...] la exacerbación universal de la dispersión individualista de las personas y de la conducta egoísta travestida de libertad individual, lo que en la práctica equivale a la universalización del "sueño americano" pervertido en la pesadilla de brutal persecución individual de riqueza y de poder contra los demás; la "fundamentalización" de las ideologías religiosas y de sus correspondientes éticas sociales [...] el uso creciente de las llamadas "industrias culturales" (sobre todo de imágenes, cine, TV, video, etc.) para la producción industrial de un imaginario de terror y de mistificación de la experiencia, de modo de legitimar la "fundamentalización" de las ideologías y la violencia represiva (p. 854). 
La colonización trajo consigo una serie de variables negativas para la convivencia en lo que hoy se conoce como Latinoamérica, implicaciones filosóficas, políticas y territoriales que por más de 500 años que dejaron pertrechos en la mente de los habitantes latinos, como analiza Fallilone (2017): no se puede olvidar "la etapa de opresión y explotación, vividos durante la colonización y usurpación de nuestro suelo por medio de los europeos" (p. 238).

Una observación central respecto de las ideologías dominantes occidentales resalta cuando surge la crítica dual al capitalismo y el marxismo (comunista y socialista), que se constituyeron en dos proyecciones que apuntan al mismo fin: el progreso. La primera, basada en la detentación privada de los medios de producción para el lucro y la segunda, buscando la concepción de esos medios de producción por las clases subalternas, en una especie de equilibrio entre el interés privado y las clases sociales, pero al mando del Estado. Sin embargo, ambas tienen la cerrazón colonial/moderna/occidental, siendo en el caso del marxismo, para Lander (2001), por ejemplo:

El propio Marx no logra superar -ni asumir plenamente en sus dimensiones epistemológicas- la tensión entre la crítica al conocimiento de la sociedad capitalista, como dimensión medular de la crítica al capitalismo, y la búsqueda de la construcción de un edificio científico a partir de los moldes epistemológicos y criterios de cientificidad propios de la sociedad capitalista, esto es, la ciencia positiva. -Esto se observa- [...] por un lado, en los textos más personales, más exploratorios, más filosóficos de Marx -como los Manuscritos de París de 1844 (Obras de Marx y Engels, 1978), los Grundrisse (Marx, 1971b, 1972 y 1976), el capítulo VI inédito de El Capital (Marx, 1971a) - y, por el otro, en la presentación más formalizada, más científica de su trabajo, que se observa en buena parte de El Capital [...]. Si la marcha de la historia se da de acuerdo con las leyes objetivas, cuya naturaleza y esencia pueden ser conocidas $-\mathrm{y}$ son de hecho conocidas- objetivamente solamente por el marxismo. La apelación a la verdad por parte del Estado socialista radicaliza el pensamiento tecnocrático cientificismo liberal, constituyéndose en fundamento epistemológico legitimador del autoritarismo de las sociedades del socialismo real (pp. 222-227).

Desde la perspectiva boliviana, sobre el debate colonialidad/decolonialidad en el continente, se apuesta a la mirada desde los márgenes históricos y recorre la contemporaneidad con los resabios indigenistas/ decoloniales, cuando se reivindica un pensamiento que considera la naturaleza y cosmovisión como centro de un pensamiento distinto. De forma 
más radical, se plantea un mundo amáutico: un sistema de vida con sabiduría respecto de la naturaleza y el cosmos, con plena dedicación para la convivencia del bien común, sin intereses individuales o privados, donde lo más importante sea la vida antes que la materia. Lejos del capitalismo lacerante o del marxismo-comunismo-socialismo, en la propuesta del boliviano Reinaga (1981), uno de los pensadores más importantes del indigenismo-indianismo latinoamericano del siglo XX, se considera que:

La única clave es: el imperativo categórico, la cósmica trinidad que proclama: 1. Sacar a Cristo y a Marx de la cabeza de los hombres. 2. Edificar la Comunidad Amaútica Mundial: el reino de la verdad y la libertad. 3. Ser lo que se es: Cosmos. La conciencia del cosmos (p. 8).

Continuando con la ontología boliviana, se plantea hoy una forma híbrida para la concepción de un pensamiento "descolonizador", la cual pretende asumir dos concepciones distintas en la posición, por ejemplo, del vicepresidente ejecutivo Álvaro García Linera (2015), quien en su libro La potencia plebeya plantea lo siguiente:

Se trata de una peculiar articulación entre las lecturas de la tradición histórica de las luchas indígenas por autonomía, con las modernas lecturas de autodeterminación de las naciones, desarrolladas por el marxismo crítico, y cuya importancia radica en que permite centrar el discurso en ámbitos territoriales específicos, en masas poblacionales verificables y en sistemas institucionales de poder y movilización más compactos y efectivos [...]. Estos dos aportes del indianismo como estrategia de poder descentrarán la enemistad de esta corriente ideológica con algunas vertientes del marxismo, dando lugar a un diálogo, ciertamente tenso, entre esta corriente indianista y emergentes corrientes intelectuales marxistas críticas, que ayudarán a definir de una manera mucho más precisa la direccionalidad de la lucha y construcción de poder político en esa estrategia indianista (p. 492).

Sin embargo, Boaventura De Sousa Santos (2013), en la ponencia La filosofía de la liberación junto a la epistemología del sur, presentada en la UACM, manifiesta la incongruencia existente en la aplicación de resabios de la modernidad-progreso, que prevalecen en el pensamiento hegemónico y perviven en los países latinoamericanos que tienen Constituciones avanzadas respecto de la visibilización de la razón indígena, pero que sus Gobiernos no condicen con las mismas en su ejercicio del poder:

Hubo transformaciones importantes en Ecuador y Bolivia, pero en este momento están en peligro, porque Constituciones avanzadas, están siendo desconstitucionalizadas, el caso del TIPNIS (Territorio Indígena 
y Parque Nacional Isiboro Sécure) en Bolivia es un ejemplo, el caso de Yasuní-ITT (Reserva Natural de la Biosfera por la UNESCO en el Ecuador); hicieron -el trazo de- una carretera que va atravesar el TIPNIS, y la exploración petrolera de Yasuní-ITT son dos violaciones totales de lo que está en las Constituciones de estos dos países ( $\mathrm{s} / \mathrm{p}$ ).

En este sentido, hay que criticar la vulneración de las Constituciones de estos países en nombre del progreso-modernidad global de las naciones, pues sus razones duras y van en contra del habitad de los seres vivos. Así, en la introducción de la Antología del pensamiento crítico boliviano contemporáneo, Silvia Rivera-Cusicanqui y Virginia Aillón (2015), vierten críticas acérrimas sobre la situación colonial en Bolivia:

En alianza con el ala masculina, sindicalera y letrada de los insurgentes, esos mestizos centralistas y habladores se hacen del poder. Toman la palabra, declaran que Bolivia ha salido de la pobreza y por fin puede prescindir de la ayuda externa [...]. El intelectual cochabambino ocupa temporalmente el centro de la escena, mientras el presidente entrega canchas de pasto sintético, estadios, hoteles y vehículos SUV a múltiples organizaciones sociales, comunidades y municipios de todos los confines [...]. En ese proceso, el cuerpo de la nación se sume en el Estado y comienza a caminar en línea recta. $Y$ en ese tiempo lineal que no tolera retrasos se acaba construyendo la historia de la modernidad boliviana. Aclaremos: es un "tiempo lineal" pero no vacío, porque está saturado de códigos y palabras que expresan en todas sus dimensiones nuestra condición colonizada (p. 15).

La colonialidad está presente en distintos tipos de estructuras sociales y gubernamentales, con motivo de promover la modernidad y desarrollo al estilo de Occidente, y está instaurado en la médula de gobernados y gobernantes en Latinoamérica. En esa línea, la pedagoga Catherine Walsh (2015), integrante del Grupo Modernidad/Colonialidad de Latinoamérica y el Caribe, respalda la crítica a propósito de la situación boliviana y su tarea descolonizadora:

Lo Decolonial, decolonialidad y descolonialización no son nuevas condiciones a ser interpretadas, implementadas o logradas por gobiernos, ni tampoco podría ser un proyecto de estructuras ni instituciones, que mantengan el modo del gobierno de autoridad, poder y control vertical, pensar entonces que los gobiernos pueden lograr, o siquiera provocar decolonialización sin transformar las nociones de autoridad y poder, es una falacia, que incluso -el Gobierno de- Evo Morales está haciéndonos nota. Lo decolonial no viene desde arriba, sino desde abajo desde los márgenes, desde los bordes, desde la gente, las comunidades, movimien- 
tos, colectivos; desde procesos otros, que retan-interrumpen y transgreden las matrices modelo-coloniales $(\mathrm{s} / \mathrm{p})$.

La colonialidad interna en Latinoamérica se evidencia en los propios Gobiernos de la región, incluidos los Gobiernos de coyuntura ideológica de izquierda, especialmente en el ámbito de la educación, donde prueban el estado de la colonialidad del saber y se desplaza al saber indígena-comunitario a segundo plano. Este es el caso de Ecuador, como señala Granda Merchán (2018):

Pone sobre la mesa -la- discusión -de- elementos concretos para reflexionar sobre la manera en que los gobiernos de "izquierda" de la región, como el del economista Rafael Correa, ha procesado la problemática de la exclusión de los pueblos indígenas y sus demandas en materia educativa. A contracorriente de las buenas intenciones expresadas en el ámbito discursivo y la normativa jurídica, parecería ser que en el Ecuador se vivió un proyecto político que terminó cooptando y desmantelando la educación de los pueblos indígenas (p. 308).

Por ello es que la decolonización debe partir desde las comunidades indígenas, desde los márgenes o los marginales (calificación interpuesta por el occidentalismo) y sobre todo desde la sabiduría de los pueblos ancestrales en la que deberá gestarse una lucha política y social, una lucha desde el saber popular no populista, desde el saber local no capitalista-marxista, desde el saber cotidiano y no desde el futuro.

\section{Cosmovisión indigena-originaria}

La decolonización del saber en América Latina desde la cultura indígenaoriginaria constituye una fortaleza, pues trata de recuperar y comprender el conocimiento ancestral y retomar la sabiduría indígena-originaria de culturas milenarias que establecen el "camino sagrado". Esta búsqueda no significa, bajo ninguna lógica, retroceder al pasado, sino re-hacerse en los principios y valores que no tienen tiempo ni espacio. Representa vivir y convivir en los valores de la "cosmovisión indígena-originaria" que constituyen los principios profundos de complementariedad del "hombre-cosmos-madre tierra", que forman un todo armónico con respeto y tolerancia, donde prevalecen los principios del ayllu-mink'a-ayni que representan la redistribución-articulación-reciprocidad. A partir de la denominada "epistemología otra", se propone la cosmovisión andinaamazónica decolonial del Abya Yala (nombre ancestral de América), que consta principalmente de: 
Desaprender y reaprender. Incursión en el despiste y sustitución cognitiva de los arquetipos occidentales. Se debe nutrir ese vacío con el aprendizaje mental de la cosmovisión indígena-originaria y reacomodar la experiencia del ejercicio, cambiando el plano del conocimiento.

Deshacer y deconstruir en la práctica. Se deben desaprender también las experiencias impuestas, esa razón de la imposición mecánica mental del occidentalismo, sustituir o restituir con el hacer de las prácticas y habilidades cotidianas de los indígenas-originarios, de las culturas subalternas marginadas por la colonialización de los saberes.

Reivindicar al hombre-mujer, la Madre Tierra (Pachamama) y el cosmos. Son un todo que viven relacionados perpetuamente. Esa totalidad, vista en la naturaleza, es para la cultura indígena-originaria un solo ser vivo. El hombre tiene un alma, una fuerza de vida, y también lo tienen todas las plantas, animales, montañas, etc., y siendo que el hombre es la naturaleza misma no puede dominarla ni debe pretender hacerlo, pues convive y existe en la naturaleza y el cosmos como un elemento más de ella. En ese sentido, para decolonizar la vida, en la visión andinaboliviana, se deben tomar los tres espacios, niveles o pachas que según Mamani (2001) posee cada grupo humano o cultura: alaxpacha o mundo de arriba, del más allá o el cielo, akapacha o mudo real y visible en el que vivimos y manqhapacha o mundo de abajo, del subsuelo. Con base en estos tres niveles se constituye el conocimiento andino.

Pensar y hacer, escuchar $y$ hablar. Todo esto hay que hacerlo desde las lenguas originarias como el quechua, aymara, leco, guaraní, mapuche, araucano, sécure, sironó, puquina, etc.

Articulación de la diversidad. Debe ser una oportunidad, capacitando alianzas, como plantea Rivera Cusicanqui (2010), articular pactos sociales inclusivos, articular la diversidad de un modo inédito y descolonizado.

Interacción del saber desde el buen vivir. Desde la sabiduría indígena, aprender y enseñar la interacción entre el "saber vivir" que implica tener armonía interna, con el "saber convivir" complementariamente con los demás, es decir, con respeto, tolerancia y concordia.

El conocimiento debe custodiar la dignidad humana. Sobre todas las situaciones, la raza es una creación colonial que denigra el ser y su saber.

Aprovechar las fisuras de la modernidad. Esto se hace a partir de su relación con el mundo indígena-originario, para operar el cambio social. Espiritualidad de la ciencia. Hay que introducirle sentimiento a la ciencia (sentí-ciencia), así como plantea Fals Borda (2015), el hombre "sentipensante" que combina la razón y el amor, el cuerpo y el corazón, 
para deshacerse de todas las (mal)formaciones que descuartizan esa armonía y poder decir la verdad.

Enseñar el conocimiento de la cosmovisión indígena-originaria. Hay que transmitirlo al común de los ciudadanos de Occidente, mostrando la alternativa de vida en plenitud en el planeta.

Organizar y concatenar. Hay que trabajar esto sobre las diferencias de los saberes de los movimientos sociales que no impiden colaborar en el encuentro decolonial.

Teorizar los saberes y prácticas de los indígenas-originarios de América. Para precisar y generar un fuerte intelecto de la sabiduría del Abya Yala.

Incentivar la apropiación de internet. Como plantea Maldonado Rivera (2015), se debe hacer comprender el uso específico que las comunidades indígenas le otorgan a las tecnologías digitales, reconociendo que estas contribuyen a que diversos grupos dejen de ser sujetos pasivos de recepción de los relatos hegemónicos y pasen a convertirse en productores simbólicos.

Diálogo o polílogo entre culturas. Como plantea Estermann (2006), el enfoque intercultural subraya la importancia del diálogo entre culturas, en este caso, entre la cultura indígena-originaria y la occidental, de igual a igual.

Complementariedad. Aproximar y juntar saberes opuestos y/o contrarios para estar completos en el conocimiento de la vida armónica.

Estos planteamientos presentados en base la filosofía andina-amazónica deben impulsar el nuevo sistema armónico de vida en/con el planeta.

\section{La comunicación para el vivir bien}

La comunicación para el vivir bien ya ha sido abordada por Adalid Contreras (2014) en el libro Sentipensamientos de la comunicación-desarrollo a la comunicación para el vivir bien, un original documento que rescata el saber andino respecto de la comunicación, de donde se gestan más elementos que precisa la decolonialización de la comunicación.

El vivir bien o buen vivir es parte de la cosmovisión andina indígenaoriginaria ancestral. Esta visión constituye, según el investigador aymara Fernando Huanacuni (2010) (actual ministro de Relaciones Exteriores de Bolivia) un paradigma comunitario de la cultura de la vida, cuyo concepto es: "Forma de vivir reflejada en una práctica cotidiana de respeto, armonía y equilibrio con todo lo que existe, comprendiendo que en la vida todo está interconectado, es interdependiente y está interrelacionado" (p. 11). 
Es en verdad un planteamiento político muy profundo que emerge desde la visión originaria-indígena. En ese fundamento se propicia el nuevo Estado Plurinacional de Bolivia, impulsado por algunos autores como David Choquehuanca, ex ministro de Relaciones Exteriores, y su lucha por recuperar y propiciar la filosofía andina. En ese propósito, Choquehuanca (2010) planteó en el Encuentro Latinoamericano Pachamama, Pueblos, Liberación y Sumak Kawsay, organizado por la Fundación Pueblo Indio del Ecuador, que:

Vivir bien y NO mejor: Bolivia plantea el Vivir Bien, no un vivir mejor a costa del otro, sino un Vivir Bien basado en la vivencia de nuestros pueblos. Vivir Bien es vivir en comunidad, en hermandad, y especialmente en complementariedad. Donde no haya explotados ni explotadores, donde no hayan excluidos ni quienes excluyan, donde no haya marginados ni marginadores. Mentir, robar, atentar contra la naturaleza posiblemente nos permita vivir mejor, pero eso no es Vivir Bien. Al contrario, Vivir Bien significa complementarnos y no competir, compartir y no aprovecharnos del vecino, vivir en armonía entre las personas y con la naturaleza. El Vivir Bien no es lo mismo que el vivir mejor, o el vivir mejor que el otro. Porque para el vivir mejor, frente al prójimo, se hace necesario explotar, se produce una profunda competencia, se concentra la riqueza en pocas manos. Vivir mejor es egoísmo, desinterés por los demás, individualismo. El Vivir Bien está reñido con el lujo, la opulencia y el derroche, está reñido con el consumismo (p. 8).

Sin embargo, de esta intención del vivir bien desborda en Bolivia una serie de conjeturas y contradicciones: es el caso de la construcción de una carretera progresista por el TIPNIS, los supuestos hechos de corrupción en el Fondo Indígena, la contaminación por la explotación de recursos naturales, entre otros hechos y acciones del ejercicio del poder que contradicen a los principios y valores del vivir bien formulados por los mismos gobernantes. La colonialización interna permea la razón indígena-originaria, contra la cual hay que luchar con denuedo, y uno de esos escenarios es la apuesta de la comunicación del buen vivir o el vivir bien, para aproximar el debate y/o diálogo entre el poder gubernamental y el saber social indígena del buen vivir.

Existen varias definiciones entorno al vivir bien en relación a múltiples propósitos tales como los de: aproximación social, política, cultural y el respeto a la vida y a la naturaleza. En este sentido, Contreras (2014) se plantea, tomando en consideración los elementos referidos ut supra, la siguiente definición de comunicación para el vivir bien: 
La comunicación para el vivir bien es un proceso de construcción, de/ construcción y re/construcción de sentidos sociales, culturales, políticos y espirituales de convivencia intercultural y comunitaria con reciprocidad, complementariedades y solidaridad; en el marco de una relación armónica personal, social y con la naturaleza; para una vida buena en plenitud que permita la superación del vivir mejor competitivo, asimétrico, excluyente e individualizante cosificado en el capitalismo y el (neo)colonialismo (p. 81).

Partiendo de esta definición, se constituye la integralidad del proceso de comunicación humana, terrenal y cósmica. Así, desde las matrices de la cosmovisión andina del vivir bien se desprenden los principios y valores sustanciales que el estudio y la práctica de la comunicación deben articular para propiciar la cultura de la vida.

\section{Recuperación de principios y valores de la cosmovisión andina-amazónica}

\section{Principios andino-amazónicos del vivir bien en la comunicación}

En este acápite se plantea la recuperación de principios provenientes del pensamiento y la práctica de vida del mundo indígena en base a planteamientos de Mamani (2001) y Contreras (2014) respecto del ejercicio comunicacional:

Complementariedad en el todo. Porque todo vive en un todo, la comunicación debe generar interconectividad. Diálogo entre los opuestos.

Sabiduría ancestral. La comunicación debe recuperar la sabiduría de los ancestros, a través del relato oral, en los vestigios de los tipos y formas de comunicación antes de Colón. Teorizar esos saberes.

Priorizar la vida. Sobre todas las cosas, hacer prevalecer todas las formas de vida, utilizando los medios necesarios para ello.

Alcanzar el consenso. Relacionar las partes y los movimientos sociales marginales y de poder, para suscitar aceptación en beneficio del interés común y del entorno, debiendo comprender las mediaciones intrínsecas de los pueblos originarios-marginales.

Vida en libertad. La comunicación debe extender sus pericias y creatividades para el ejercicio de la libertad de vida, pensamiento, y expresión de manifestaciones culturales de los pueblos en todas sus formas nativas.

Equilibrio con la Pachamama. Es vital alertar, defender y reconstituir el equilibrio con la madre tierra, a través de espacios de encuentro con la 
naturaleza. Comunicación del ser humano Con. las montañas, los ríos, lagos y mares, el viento, con los árboles, con la tierra, con todos los seres vivos.

Dignidad e identidad. Generar movimiento, resistencia, lucha, defensa, conquista de la dignidad de los pueblos excluidos por la modernidad, a través del diálogo de saberes.

Espiritualidad profunda. Conectar o hacer que se conecte uno mismo, con su Dios-Deidad, con el cosmos, con la energía.

Preservar la comunidad. Promover común-unión de los pueblos, resguardar articulando el encuentro de la comunidad y comunidades distintas, para integrar la gran comunidad.

Autodeterminación de los pueblos. Decolonizar los pueblos a través del reconocimiento de la plurinacionalidad, diversidad; incentivado el autorreconocimiento de su identidad y la del pueblo, a través de conexión de la intra e interculturalidad de luchas indígena-originarias.

Rotación de los espacios. Propiciar, comunicar el ciclo agrícola de siembra y descanso de las parcelas. Así como el acatamiento de los ciclos de mandato.

Valores andino-amazónicos del vivir bien en la comunicación

De la misma manera, ahora se plantean los valores que provienen del pensamiento y la práctica indígena del vivir bien, como compromiso comunicacional ligado con el giro decolonial y la responsabilidad con la cultura de la vida:

Respeto. Propiciar el respeto al otro con sus diferencias y similitudes.

Tolerancia. Promover la paciencia y serenidad ante la adversidad.

Inclusión. Insertar y unificar componentes marginados del vivir bien.

Armonía. Trascender las separaciones culturales para la convivencia amistosa.

Articulación. Es el término comunicacional que constituye la relación social como un valor ancestral, para constituir la misma se tiene que identificar y comprender las mediaciones culturales y luego movilizar el proceso.

Reciprocidad. Promover y expandir la cultura del ayni (la colaboración). hoy por ti mañana por mí. Incentivar la ayuda colectiva, y la correspondencia mutua.

Unidad-integración. Preservar el ayllu, que significa vincular la familia, el grupo, la comunidad, la vida en comunidad.

Para finalizar, se debe efectuar una advertencia: la auténtica filosofía-cosmovisión andina y amazónica, no pretende la anulación del otro solo porque piensa y actúa diferente, busca la unidad en la diversidad. Por lo tanto la comunicación y la comunicología debe ser un servicio social para el interés del bien común. 


\section{La nueva comunicación alternativa desde la matriz de Luis Ramiro Beltrán}

Pensar en una alternativa latinoamericana del pensamiento comunicativo debe partir necesariamente desde la teoría crítica sobre el estudio de la comunicación legada por el comunicólogo boliviano Luis Ramiro Beltrán Salmón, que interpone, junto con otros comunicólogos de la región a partir de 1970, críticas certeras sobre el uso de la información y la comunicación con afanes de dominación por parte de Occidente, en especial por EE.UU., sobre Latinoamérica. Esa historicidad en la producción de conocimientos en la región sobre teoría crítica de los procesos comunicacionales se constituye en la base del nuevo pensamiento crítico de la comunicación, cuyos precursores son baluartes en este propósito: Luis Ramiro Beltrán, Juan Díaz Bordenave, Antonio Pasquali, Mario Kaplún, entre otros. Innovadores como Armand Mattelart, Jesús MartínBarbero, José Marques de Melo y otros, con sus aportes constituyen el cimiento y la estructura sólida para plantear hoy la "decolonialización de la comunicación".

En el libro La comunicación antes de Colón: tipos y formas en Mesoamérica y los Andes (Beltrán et al., 2008) se destaca una investigación donde se evidencian los legados comunicacionales antes de la llegada de Cristóbal Colón a Latinoamérica:

Se pudieron reconocer los siguientes tipos comunicacionales: La comunicación oral, la comunicación gesto-espacial-sonora, la comunicación escrita, comunicación iconográfica y comunicación gesto espacio monumental [...]. Pero ya dentro delas formas - por ejemplo- que asumen estos distintos tipos se pueden encontrar, una escritura nativa precolombina expresada materialmente a través de códices, pallares, estelas, tejidos, etcétera. Vale decir, distintas formas para el tipo escrito (p. 21).

El aporte de Beltrán (1985) incursiona también en documentos críticos y muy visionarios sobre premisas, objetos y métodos foráneos en la investigación sobre comunicación en América Latina, donde se discute sobre la colonialidad del estudio de la comunicación y a partir de ello se formulan antecedentes que siguen vigentes hasta hoy:

Surgirá en el futuro próximo (cobijada por una sociología que no sea de ajuste y por una psicología de in-conformismo) una comunicología de liberación que debe ayudar a forjar la América Latina que la mayoría de sus trescientos millones de seres humanos desean y merecen (p. 18). 
Al decir de Beltrán (1985), los investigadores continúan alejados de la realidad y del contexto social latinoamericano, así como de las necesidades de la gente que habita en la región, aunque existen iniciativas muy particulares que fructificaron la investigación hecha desde Latinoamérica con un pensamiento propio. Por ejemplo, la encuesta por muestreo pudiera comprenderse bajo la visión alternativa como un "moledor de gente", explicándose que este tipo de métodos foráneos todavía evidencian resultados positivistas con fines de control, simplismo y reduccionismo del estudio comunicacional, donde se minimiza a los individuos a números pasivos, porcentajes que consumen cierto producto a través del uso de la información persuasiva, como la publicidad y la propaganda. Son tipos de investigación que utilizan métodos y técnicas demoledoras en pro de la deshumanización.

Los planteamientos teóricos de una comunicación libertaria en América Latina se iniciaron a partir de la década de los setenta, con posturas críticas frente a la dependencia de la teoría y práctica funcionalistapositivista de la comunicación, especialmente mediática, en la búsqueda de los efectos de los mensajes emitidos que se desplazan por los canales. Luís Ramiro Beltrán se constituye así en uno de los precursores de la "comunicología de la liberación", que busca comprender el proceso de la comunicación de forma integral y dinámica, en el cual todos los componentes son importantes e inseparables. Erick Torrrico (2012), en su ponencia Luis Ramiro Beltrán y la comunicología de la liberación, refiere que:

Esa fecundidad analítica, asumida hoy como fuente del pensamiento decolonial que busca la independencia epistémica de la región frente al histórico predominio eurocentrista, en 1976 se irguió la CdL -Comunicología de la Liberación- prefigurada por Luis Ramiro Beltrán como alternativa propia ante las condiciones de supeditación que asignaban a la investigación y a la planificación comunicacionales. Su expectativa fue que como parte de esa nueva Comunicología -como indica Beltrán-: Tal vez se logrará una conciliación programática y libre de dogma entre la lúcida intuición y la medición valedera que conduzca al óptimo empleo de la diversas tendencias de las diferentes técnicas, así como a la creación de conceptos y procedimientos genuinamente adecuados a la región (p. 57).

Para asumir los retos teóricos decoloniales se deberá voltear la visión en el estudio de la comunicación, debe observarse los fenómenos o necesidades de comunicación de abajo hacia arriba, desde las multitudes que demandan al poder colonial; debe provocarse aquello desde las marginalidades, como señalaba Catherine Walsh (2015), donde el hecho decolonial 
es un proceso dinámico, un proceso de hacerse y rehacerse dada la permanencia y la capacidad de reconfiguración de la comunidad del poder, es un proceso de lucha no solo contra, sino para modos otros de ser, estar, pensar, saber, sentir y vivir, un proceso que engendra, invita a la alianza, brinda conectividad, articulación y correlación, lucha por la invención, creación e intervención, por sentimientos significados, horizontes y hasta educaciones y comunicaciones prácticamente distintas. Esto es parte integral de la pedagogía de las grietas decoloniales, de agrietar extender y ensanchar, es una pedagogía de las prácticas, de hecho, comunicativas.

En el acto inaugural del I Congreso Internacional: Comunicación, Decolonialización y Buen Vivir, Francisco Sierra (2015), ex director de CIESPAL, reflexionaba respecto del rol de la nueva academia en el estudio de la comunicación y sobre la tarea de las universidades en la formación de nuevos comunicadores:

Se debe generar un nuevo debate, que tome como punto de partida y llegada las identidades silenciadas, o reprimidas del indigenismo, cuya tradición milenaria hoy debe ocupar una función protagónica en la defensa de una política científica, que asuma radicalmente el principio de diversidad cultural, nos llama la atención desde CIESPAL que pese a los avances de regulación en el sistema informativo, en el derecho de acceso de esas minorías, en el reconocimiento de la diversidad lingüística, la investigación en comunicación regional margine en sus currículos formativos en la universidad de manera sistemática cualquier pretensión de abordar ese hecho de la diversidad, señalamos antes la ausencia de estudios de comunicación comunitaria en las facultades y en la academia, pero también de comunicación intercultural de las experiencias de lucha de estos colectivos, también una práctica y método de enseñanzaaprendizaje basada en el diálogo de saberes. Sigue siendo episódica o invisivilizada como objeto de estudio y agenda de trabajo la rica pluralidad de las luchas de culturales nativas y sus mediaciones, tanto en los medios comunitarios, como en el espacio público (s/p).

Ahora se asumen esas raíces participatorias-alternativas practicadas por los pueblos marginados por la Colonia y teorizadas por grandesvalientes pensadores de siglo pasado. Tal es el caso de las radios mineras de Bolivia -que emergieron como insurrectas al poder establecido- o el "movimiento de comunicación participatoria" -que sirve a la gente para recrear su imaginario y constituir su propio cambio social-. Este tipo de comunicación, como indica Beltrán (2014):

Es otra de las creaciones de la justiciera imaginación latinoamericana; busca renovar la teoría y la práctica de la comunicación de manera que 
el pueblo -y no las élites conservadoras- sean protagonistas de ella. Se dedica a propiciar formatos innovadores, de grupo y aún masivos -la radio alternativa- que permitan el diálogo equilibrado y democrático, en vez del monologo del dominador sobre los dominados (p. 73).

Desde esas matrices alternativas que constituyen la base teóricopráctica de un ejercicio distinto a la comunicación comercial-occidental, Erick Torrico (2015a) formula una serie de elementos para la nueva comunicación alternativa, basado en sustentos decolonizadores y en la comunicología de la liberación de Beltrán. En ese razonamiento plantea, primero, una crítica de doble constreñimiento: el episteme moderno y el desarrollo, que refiere acerca de una comunicación actualmente "occidento-centrada", en segundo lugar plantea una comunicación instrumentalizada. Para ello presenta un doble reto: la des-occidentalización y decolonización de la comunicación como una perspectiva subalterna desde América Latina. Esos niveles de decolonización comunicacional serían: restitución del sentido antropológico y social del proceso, desmediatización del concepto, recuperación de la circularidad y la integralidad del proceso, establecimiento de un espacio de conocimiento propio en tanto mirada especializada sobre el mundo social, actualización del vínculo entre comunicación y emancipación (personal-colectiva). Se plantea, en esa razón una nueva comunicación alter/nativa, cuya base es la comunicología de la liberación, una propuesta que significa des-instrumentalización y humanización en una revuelta múltiple, epistemológicaontológica-teórica-metodológica-práctica y en esta última se constituye la decolonización del hacer comunicación.

Para Erick Torrico (2015b) decolonizar la comunicación, en definitiva, significa "dejar de ver la comunicación y su campo con los ojos de la tecnocracia, del mercado, la fe enceguecida y el control político, para recuperar el contenido liberador de su sentido y praxis" ( $\mathrm{s} / \mathrm{p})$. Desde esta propuesta se constituye la nueva comunicación alternativa, para trabajar la idea decolonizadora en la academia: el saber y el hacer comunicación, precisamente en la imbricación de estos dos componentes decolonizadores.

\section{El horizonte próximo de la comunicología decolonial- liberadora en Latinoamérica}

Manuel Chaparro (en Beltrán, 2014b) afirma que de una vez se debe entender que las llamadas periferias no son lugares a los que acudir para hacer rescate, más bien se debe escuchar, ver y aprender -algo que pocos 
hacen-. Seguramente se entendería mejor el mundo y la historia aceptando y travistiéndonos en la otredad, descolonizándonos de los imaginarios que han marcado esa intrínseca sabiduría de superioridad de la cultura blanca occidental, invisibilizando otros conocimientos, rutas y realidades.

En ese cometido, hoy el estudio y la práctica comunicacional debe aprender de la sabiduría ancestral, escuchar su clamor de reivindicación $y$, por lo mismo, consolidar un pensamiento propio-del-sur, cuyo sustento filosófico trascienda la ciencia pro capitalista y prevalezca la cienciaconocimiento con base en la cosmovisión indígena-originaria para una vida armónica.

En ese sentido, Francisco Sierra (en Beltrán, 2014a) afirma que se deben replantear las premisas del estudio de la comunicación desde la simiente de la decolonización:

Para construir una Epistemología del Sur para la Comunicología Latinoamericana, como rearticulación de la teoría crítica de la mediación social, basada en la cultura académica emancipatoria y antagonista de la Escuela Latinoamericana de Comunicación (ELACOM) -propuesta por José Marques de Melo-, no partiremos de cero. De Freire a Escobar, de Martín Barbero a García-Canclini a Dussel y a Quijano, y los estudios poscoloniales, pasando por Boaventura de Sousa Santos, la puesta por la decolonialidad del saber-poder informativo, nos plantea el reto de reformular las bases del discurso científico comunicacional a partir de una crítica del poder mediador del pensamiento hegemónico angloamericano, a partir de las matrices culturales del paradigma amerindio sobre el que Luis Ramiro Beltrán se introdujo (p. 13).

En esas criptas o fisuras de la modernidad capitalista, en la destrucción del planeta que incentiva el capitalismo de muerte, ya está más que fehaciente la emergencia de un episteme otro, que ha nacido y ha crecido para andar por el camino de la liberación y ahora por su posesión en el mundo. Un episteme otro que ya se ha madurado bastante con la crítica a la ciencia eurocentrista y por eso ahora el reto es confirmar no solo un paradigma, sino una matriz de largo aliento, constituida en la cosmovisión de la comunicación para una vida en armonía y plenitud. Entonces, es urgente considerar un diálogo con Occidente desde la base filosóficacultural nativa del Abya Yala, como remarca Díaz Salazar (2015):

La última expresión de esa comunidad social, llámese indígena, afroecuatoriana, montubia y popular, es la nacionalidad; por lo que la base ontológica de la nacionalidad es la sociedad comunitaria. El presente y futuro del sujeto de Abya Yala está en la sociedad comunitaria y de nacionalidad (p. 60). 
En este decurso se apunta también que es importante la divulgación del pensamiento decolonial latinoamericano entre los pueblos latinoamericanos y de Occidente, para ingresar en el debate de frente con el conocimiento eurocentrado-occidental. Diseminar el diálogo de saberes entre las culturas que habitan Latinoamérica y también el diálogo con Occidente. Se debe, entonces, realizar un trabajo profuso de divulgación en lenguas originarias, además del español, inglés y otras.

En el decurso decolonial del saber y hacer en las universidades, se debe debatir y actuar de frente: social, política y epistemológicamente, con el conocimiento occidental sobre la razón de estar en el mundo y el universo, y es en ese diálogo de saberes donde la comunicación debe actuar, participar interna y externamente en la conexión-articulación de causas, saberes y razones que nos llevan a practicar la cultura de la vida.

\section{Conclusiones}

Desde una categoría decolonizadora, los principios y valores del vivir bien son parte sustancial de la cosmovisión andina-amazónica, que permiten repensar un nuevo horizonte de estudio y ejercicio de la comunicación, así como rescatar estos principios y valores permite que en el estudio y el ejercicio de la comunicación prevalezca la cultura de la vida.

La nueva comunicación alternativa deja de lado la razón meramente instrumental de la comunicación y recupera su razón de ser, en tanto y cuanto centre su estudio y ejercicio en beneficio del ser humano; recupera la comunicación nativa y distinta a los propósitos del mercadoprogreso, donde el saber y el hacer comunicación -al decir con Luís Ramiro Beltrán y Erick Torrico- se basa en la horizontalidad, circularidad y la integralidad del proceso de comunicación, estableciendo un espacio de conocimiento propio sobre el mundo comunicacional y social.

Es imperiosa la necesidad de que el conocimiento occidental asuma otros tipos de conocimiento como el de la visión indígena-nativa de América Latina, como la cultura andina-amazónica, para una vida en plenitud y armonía entre seres humanos en la "casa común" (planeta Tierra), que todos debemos cuidar. La auténtica filosofía-cosmovisión andina y amazónica no pretende la anulación del otro solo porque piensa y actúa diferente, busca la unidad en la diversidad. Por ello debe existir un diálogo de saberes sincero y sin supremacías para una vida armónica. 


\section{Bibliografía}

AILLÓN, Virginia \& RIVERA-CUSICANQUI, Silvia

2015 Antología del pensamiento boliviano contemporáneo. Buenos Aires: CLACSO.

BELTRÁN, Luis Ramiro

1985 Premisas, objetos y métodos foráneos en la investigación sobre comunicación en América Latina. En M. Moragas (ed.), Sociología de la comunicación de masas, tomo II (pp.73-107). Barcelona: Gustavo Gilli.

2007 Un adiós a Aristóteles: la comunicación "horizontal". Punto Cero, 12(15), 69-92. Recuperado de https://bit.ly/2SdyBtV [consulta 21/06/2018].

2014a Comunicación, política y desarrollo. Quito: CIESPAL.

2014b Comunicología de la liberación, desarrollismo y políticas públicas. Málaga: Luces de gálibo.

BELTRÁN, Luis Ramiro, HERRERA, Karina, PINTO, Esperanza \& TORRICO, Erick

2008 La comunicación antes de Colón: tipos y formas en Mesoamérica y los Andes. La Paz: CIBEC.

CASTRO-GÓMEZ, Santiago \& GROSFOGUEL, Ramón

2007 El giro decolonial: reflexiones para una diversidad epistémica más allá del capitalismo global. Bogotá: Siglo del Hombre.

CONTRERAS, Adalid

2014 Sentipensamientos de la comunicación-desarrollo a la comunicación para el vivir bien. Quito: UASB/Ediciones Tierra.

CHOQUEHUANCA, David

2010 Hacia la reconstrucción del Vivir Bien. En Encuentro Latinoamericano: Pachamama, Pueblos, Liberación y Sumak Kawsay (pp. 8-13). Quito: Fundación Pueblo Indio del Ecuador/ALAI.

DE SOUSA SANTOS, Boaventura

2013 Decolonización epistemológica del sur. Recuperado de https://bit.ly/2P4JOv5/

DÍAZ SALAZAR, Holger Rodrigo

2015 La hermenéutica como método para comprender la colonialidad del sujeto de Abya Yala. Sophia, Colección de Filosofía de la Educación, (19) [doi: 10.17163/soph.n19.2015.02].

ESTERMANN, Josef

2006 Filosofía andina: sabiduría indígena para un nuevo mundo. La Paz: ISEAT.

FALS BORDA, Orlando

2015 Una sociología sentipensante para América Latina. Recuperado de https://bit. ly/24iIcyv/

FALLILONE, Emiliano

2017 Buscar y forjar una identidad latinoamericana desde el aula. Sophia, 1(22), 233-253. Recuperado de https://bit.ly/2ApWeIn/

GARCÍA LINERA, Álvaro

2015 La potencia plebeya: acción colectiva e identidades indígenas, obreras y populares en Bolivia. Buenos Aires: CLACSO/Siglo XXI. 
GONZÁLEZ-SAMÉ, Héctor, ROMERO-RODRÍGUEZ, Luis Miguel \& AGUADED, Ignacio

2017 La investigación en comunicación en Latinoamérica: una aproximación histórica (1950-2016). Historia y Comunicación Social, 22(2), 427-443. Recuperado de https://bit.ly/2DMzDZR/

GRANDA MERCHÁN, Juan Sebastián

2018 Transformaciones de la educación comunitaria en los Andes ecuatorianos. Sophia, Colección de Filosofía de la Educación, (24), 291-311. Recuperado de https://bit.ly/2DXWgf1/

HUANACUNI, Fernando

2010 Buen Vivir / Vivir Bien: filosofía, políticas, estrategias y experiencias regionales andinas. Lima: CAOI.

LANDER, Edgardo

2000 La colonialidad del saber: eurocentrismo y ciencias sociales. Perspectivas latinoamericanas. Buenos Aires: CLACSO.

2001 Marxismo, eurocentrismo y colonialismo. Recuperado de https://bit. ly/2SavCT0/

MALDONADO RIVERA, Claudio

2015 Decolonialidad, tecnologías y comunicación: un estudio de caso. Recuperado de https://bit.ly/2zrZl33/

MAMANI, Félix

2001 Síntesis histórica de la cultura: Oruro. Oruro: CEPA.

MELGAR, Tirso (ed.)

2015 Modernidad/colonialidad/descolonialidad: aclaraciones y réplicas desde un proyecto epistémico en el horizonte del bicentenario. Revista Pacarina del Sur. Recuperado de https://bit.ly/2DZ7DDm/

MONTENEGRO, Carlos

1982 Nacionalismo y coloniaje. La Paz: Los Amigos del Libro.

QUIJANO, Aníbal

2014 Cuestiones y horizontes: de la dependencia histórico-estructural a la colonialidad/descolonialidad del poder. Buenos Aires: CLACSO.

2015 Colonialidad del poder, globalización y democracia. Recuperado de https:// bit.ly/2QpqoFK/

REINAGA, Fausto

1981 El hombre. La Paz: CAM.

RIVERA CUSICANQUI, Silvia

2010 Oprimidos pero no vencidos: luchas del campesinado aymara y qhechwa 19001980. La Paz: WA-GUI.

SIERRA, Francisco

2015 Inauguración. En I Congreso Internacional: Comunicación, Decolonialización y Buen Vivir. Quito: CIESPAL.

TORRICO, Erick

2012 Luis Ramiro Beltrán y la comunicología de liberación. Memoria Académica Asociación Boliviana de Investigadores de la Comunicación. V Ciclo de Estudios Especializados en Comunicación (pp.54-58). Cochabamba: ABOIC.

2015a La comunicación “occidental”. Oficios Terrestres, 1(32), 3-23. Recuperado de https://bit.ly/2SgbYF8/ [consulta 08/03/2018]. 
2015b Decolonizar la comunicación. En I Congreso Internacional: Comunicación, Decolonización y Buen Vivir. Quito: CIESPAL.

WALSH, Catherine

2005 Pensamiento crítico y matriz (de)colonial: reflexiones latinoamericanas. Quito: UASB/Abya-Yala.

2015 Comunicaciones otras. En I Congreso Internacional: Comunicación, Decolonialización y Buen Vivir. Quito: CIESPAL.

Fecha de recepción de documento: 30 de marzo de 2018 Fecha de revisión de documento: 20 de mayo de 2018

Fechas de aprobación de documento: 22 de junio de 2018

Fecha de publicación de documento: 15 de enero de 2019 